\title{
FROTH DENSITY PROFILES AND FROTH HEIGHT ON PERFORATED PLATE
}

\author{
HAJIME UNNO* AND ICHIRO INOUE ${ }^{1}$ \\ The Institute of Physical and Chemical Research, Wakō, 351
}

\begin{abstract}
Some features of froth density distribution on a perforated plate and their effects on froth height are discussed both experimentally and theoretically.

The following results are obtained:

1) Horizontal profiles of froth density in the region between the crest of outlet weir and the froth surface are uniform, while those near the plate surface are non-uniform. The vertical profiles of froth density in the region where the horizontal profiles are uniform are explained by a theoretical equation derived on the assumption that the sum of potential and kinetic energies of froth volume is minimum under steady-state conditions.

2) By this equation mentioned above, the height of the region between the froth surface and the crest of outlet weir is found to be proportional to the square root of the liquid flow rate. This relation is almost independent of the gas flow rate.
\end{abstract}

\section{Introduction}

As the froth height is one of the most basic parameters for both design and operation of plate towers, many investigations have been performed to get an equation relating the froth height to process variables. However, almost all the equations proposed so far give different values of the froth height under the same conditions. This may be due to insufficient understanding of the characteristics of froth.

Local froth density on a plate may be one of the contributing factors to the froth characteristics. The froth density is defined by the volume ratio of liquid to froth around any point in the froth layer.

In this paper, the froth density profiles on a plate are discussed both experimentally and theoretically. In consideration of the froth density profiles, the relation between the froth height and the process variables is discussed.

\section{Experimental Apparatus and Procedure}

The plate tower consisted of a rectangular acrylic column fitted with two brass perforated plates $30 \mathrm{~cm}$ wide, $39 \mathrm{~cm}$ long and $4 \mathrm{~mm}$ thick. To get a uniform distribution of gas flow, one of the plates was set under the plate to be examined. Experiments were performed with two types of plate, with holes of $4 \mathrm{~mm}$ and $8 \mathrm{~mm}$ diameter drilled at $15 \mathrm{~mm}$ and $30 \mathrm{~mm}$ triangular pitches, respectively. These two types of plate had the same free area of $6.7 \%$.

Experiments were carried out in the range of water

Received October 16, 1975.

1 Tokyo Institute of Technology flow rate of $10-60 \mathrm{~cm}^{3} / \mathrm{sec} / \mathrm{cm}$ width of weir, superficial air velocity of $20-220 \mathrm{~cm} / \mathrm{sec}$ and outlet weir height of $1-7 \mathrm{~cm}$.

The froth density profiles were measured by a probe. The probe tip is made from $0.2 \mathrm{~mm}$ enameled wire. The probe method ${ }^{4}$ gives a local froth density as a time-average of liquid volume fraction at probe tip over 10-second measurement. The probe was calibrated with the liquid hold-up on the plate, which was measured by a tracer impulse method.

As the froth height varies with time, the timeaverage of liquid volume fraction is not necessarily zero at the time-averaged froth height. Within the range of this experiment, it was found that the timeaveraged froth density had a value of about 0.02 at the time-averaged froth height. So the froth height was determined by the value when the measured froth density became 0.02 .

\section{Results and Discussion}

\section{Froth density profiles}

Horizontally averaged vertical profiles of froth density on the plate have been measured by Bernard et al. ${ }^{3)}$, Pinczevski et al. ${ }^{6)}$, Takahashi et al. ${ }^{10)}$, and Tulyaev $^{11)}$ using a $\gamma$-radiation absorption technique, and by Steiner ${ }^{8)}$ using a manometer.

Bernard et al. ${ }^{3)}$ have shown that the vertical distribution of froth density varies locally, especially in the vicinity of the plate surface. However, they have not interpreted the variation.

This variation may have been caused by the plate structure. Fig. 1 shows a typical example of the froth density profiles. This profile is depicted by 
lines of equal froth density $\varphi(x, 0, z)$ in a vertical plane through a line A-A. The co-ordinate system is shown in Fig. 1. The left figure in Fig. 1 represents a vertical profile of froth density on a line through the center of a hole.

Fig. 1 shows that the froth density on the plate is distributed not only vertically but also laterally. From this result it is confirmed that the horizontally averaged vertical profiles of froth density in the planes through lines B-B and C-C are different from each other, especially in the vicinity of the plate surface. This result coincides with the experimental data of Bernard et al. ${ }^{3}$ )

Fig. 1 shows also that there exists a region where the horizontal profiles are uniform. This region is the upper part of the froth layer. In this region, the froth density may be represented by a function of only the distance from the plate, $z$. This function is expressed as $\varphi(z)$. Let $z_{m}$ be the height above which the horizontal profiles of froth density are uniform. In Fig. 2 the values of $z_{m}$ are plotted against the superficial gas velocity, $U_{g}$. These values of $z_{m}$ are measured over the range of outlet weir height between 1 and $7 \mathrm{~cm}$, superficial gas velocity between 50 and $200 \mathrm{~cm} / \mathrm{sec}$ and liquid flow rate per unit weir width between 10 and $60 \mathrm{~cm}^{3} / \mathrm{sec} / \mathrm{cm}$ of weir width. Except for the case of $1 \mathrm{~cm}$ outlet weir height, all the values of $z_{m}$ are less than those of the height of outlet weir, $W$. This result reveals the fact that the froth density profiles in the range between the crest of outlet weir and the froth surface are horizontally uniform when the outlet weir is higher than $3 \mathrm{~cm}$.

The froth density profiles on the plate have been discussed theoretically by Azbel ${ }^{1,2)}$, Kolár ${ }^{5)}$ and Takahashi et al. ${ }^{9}$. These theories are based on hypotheses that the horizontal profiles of froth density are uniform and the vertical profiles are determined by the condition that the sum of potential, kinetic and surface energies is minimum, or the total dissipation energy of froth volume is minimum in the steady state.

From both these theoretical considerations and the results of Fig. 1 and Fig. 2, a theoretical approach similar to that mentioned above is concluded to be applicable to the froth layer in the range where the froth density is horizontally uniform.

Gas bubbles in the froth layer entrain some liquid. The liquid volume entrained by gas bubbles depends on the froth density $\varphi(z)$, because it disappears at the froth surface and is finite in the froth layer. When the gas flow rate is very low, the bubbles behave independently of each other and are accompanied by some liquid volume which is proportional to the bubble volume. The liquid volume entrained by gas bubbles may depend also on the gas flow rate.

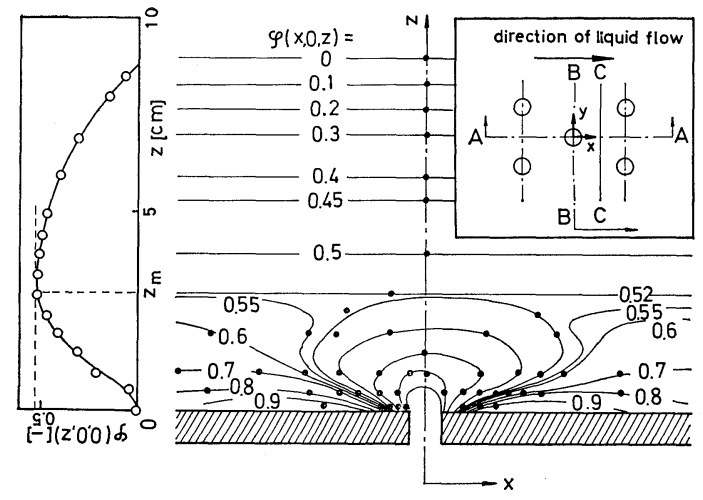

Fig. 1 An example of froth density profiles

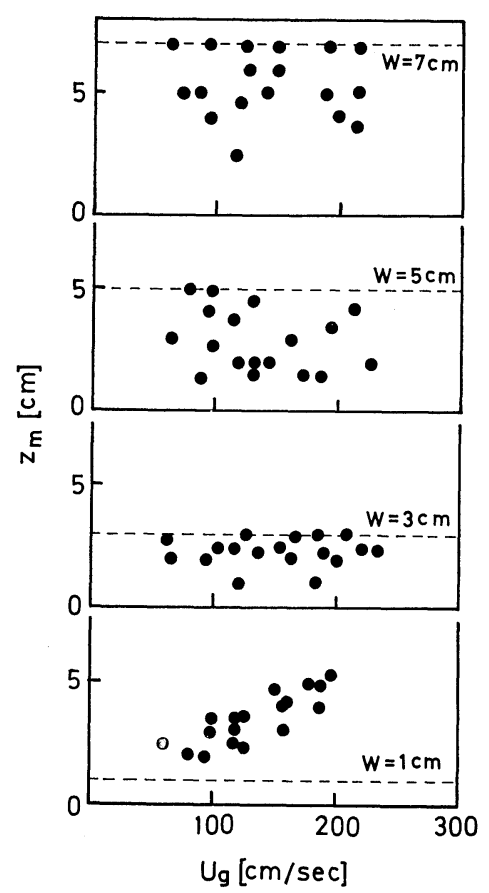

Fig. 2 Values of $z_{m}$

From the above considerations, it is reasonable to suppose that the liquid volume entrained by gas bubbles per unit froth volume at a fixed gas flow rate is proportional to the product of the volume fractions of gas and liquid.

$$
V=\alpha \varphi(z)\{1-\varphi(z)\}
$$

where $\alpha$ is a constant. The value of $\alpha$ is supposed to vary with the gas flow rate.

It is supposed that the froth density profiles are determined under the condition that the total mechanical energy of froth, $E$, that is, the sum of potential and kinetic energies including the effect of the liquid volume entrained by gas bubbles, is minimum in the steady state. When the gas flow rate is not too low, the surface energy of bubbles is neglected, because it is small compared with the other terms.

The infinitesimal change in the total energy $E$ according to the infinitesimal change in $\varphi(z)$ is given 


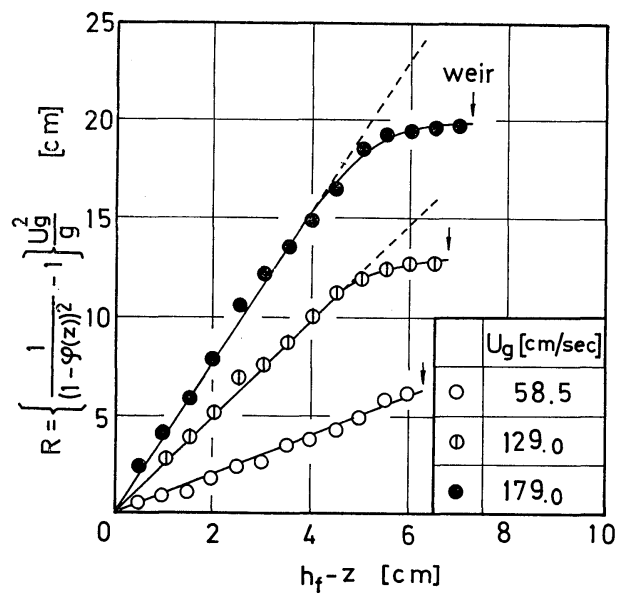

Fig. 3 Comparison of experimental data with Eq. (4)

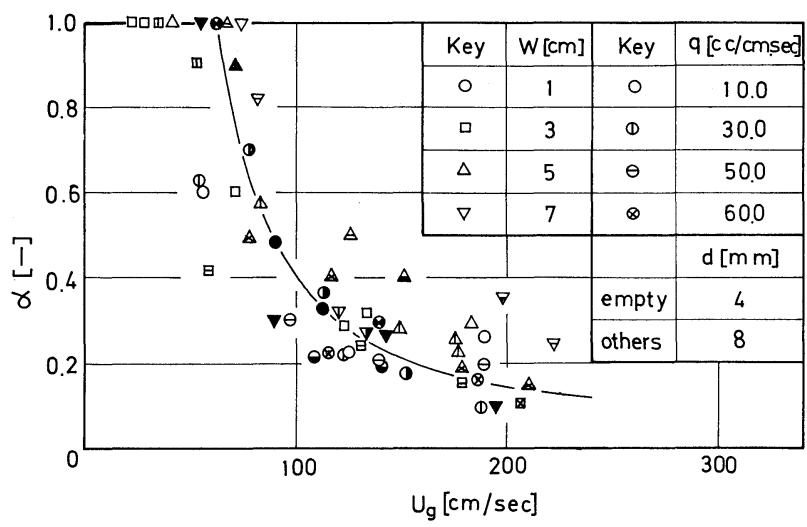

Fig. 4 Values of $\alpha$

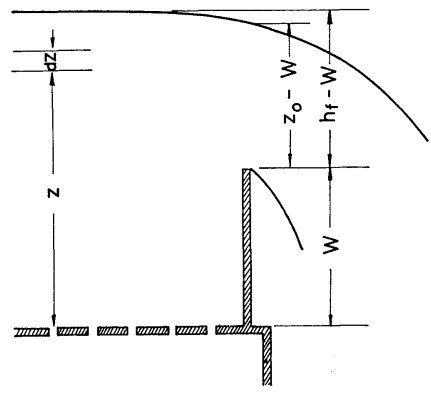

Fig. 5 Schematic representation of froth flow over weir

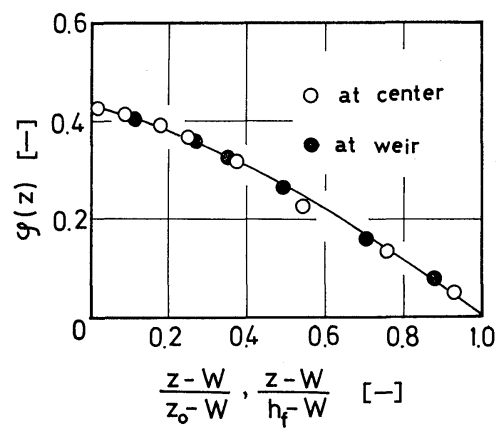

Fig. 6 Froth density profiles measured along $z$-axis by Eq. (2), if the density of gas is neglected compared with that of liquid.

$$
\delta E=\delta \int_{h_{f}-h_{f}^{\prime}}^{h_{f}}\left\{\varphi(z) \rho g z+\frac{\alpha}{2} \rho \varphi(z) \frac{U_{g}^{2}}{1-\varphi(z)}\right\} d z
$$

If the liquid hold-up in the froth layer is assumed to be constant, the following conditions are satisfied:

$$
\left\{\begin{array}{c}
\int_{h_{f}-h_{f}^{\prime}}^{h_{f}} \varphi(z) d z=\text { constant } \\
\varphi\left(h_{f}\right)=0
\end{array}\right.
$$

To determine the froth density profile $\varphi(z)$ so as to minimize the total energy, $E$, the variational method is applied to Eqs. (2) and (3). Then, the following equation is obtained:

$$
\begin{aligned}
\varphi(z) & =1-1 / \sqrt{1+\frac{1}{\alpha F r} \frac{h_{f}-z}{h_{f}^{\prime}}} \\
F r & =U_{g}^{2} / g h_{f}^{\prime}
\end{aligned}
$$

where $F r$ is Froude number.

To check Eq. (4), the experimental values of the term, $R=\left\{1 /(1-\varphi(z))^{2}-1\right\} U_{g}^{2} / g$, are plotted against $h_{f}-z$ in Fig. 3. If Eq. (4) holds, $R$ must proportional to $h_{f}-z$. Fig. 3 shows that Eq. (4) holds approximately throughout the whole range between the crest of outlet weir and the froth surface. With increase of gas velocity, the experimental data deviate a little from Eq. (4) in the vicinity of the height of outlet weir. However, the deviation is small, so the froth density profiles may be approximated by Eq. (4). From the slope of the straight line in Fig. 3, the constant $\alpha$ can be obtained.

The values of $\alpha$ thus obtained are plotted against the superficial gas velocity, $U_{g}$, in Fig. 4. From Fig. 4 the values of $\alpha$ are concluded to be independent of both the geometrical condition of the plate and the liquid flow rate, and be a function of only the superficial gas velocity.

When the superficial gas velocity, $U_{g}$, is less than about $63 \mathrm{~cm} / \mathrm{sec}, \alpha$ takes a value 1.0 . This means that the liquid volume entrained by gas bubbles is constant when the gas velocity is small. When $U_{g}$ is greater than about $63 \mathrm{~cm} / \mathrm{sec}$, the values of $\alpha$ decrease sharply as $U_{g}$ increases.

The relation between $\alpha$ and $U_{g}$ is approximated by the following equation:

$$
\alpha= \begin{cases}24 /\left(U_{g}-40\right) & U_{g}>63 \mathrm{~cm} / \mathrm{sec} \\ 1 & U_{g} \leqq 63 \mathrm{~cm} / \mathrm{sec}\end{cases}
$$

where the superficial gas velocity, $U_{g}$, is measured in the units of $\mathrm{cm} / \mathrm{sec}$. The solid line in Fig. 4 represents Eq. (5).

Relation between froth height and gas/liquid flow rate

Many previous works have correlated the froth height only empirically with operational variables such as the height of outlet weir and the flow rate of gas and 
liquid. By the froth density profile of Eq. (4), the froth height may be related theoretically to the liquid flow rate over the crest of outlet weir.

Fig. 5 shows a schematic illustration of the froth flow over the weir. Froth gradient on the plate is so small that its effect on the froth flow may be neglected. However, the difference between the froth height at the outlet weir, $z_{0}$, and that at the center of the plate, $h_{f}$, is not negligibly small, as shown in Fig. 5. This is due to the froth flow over the weir.

Fig. 6 shows a comparison of the vertical profiles of froth density at the outlet weir with that at the center of plate. From Fig. 6 these froth density profiles are concluded to be similar. From this fact, it is assumed that the driving force for the froth flow over the outlet weir can be a liquid head acting on the horizontal plane at the crest of outlet weir.

If the gas bubbles in the froth layer are supposed to be stationary, the head acting on the horizontal plane at co-ordinate $z$ is $\int_{z}^{h f} \rho \varphi(z) d z$. However, the head is actually decreased by the liquid entrained by the moving gas bubbles.

The flow pattern of froth is so complicated that it is difficult to make an accurate theoretical evaluation of the decrease of the head. From the above considerations, the effective head acting on the horizontal plane at co-ordinate $z$ is assumed to be given by

$$
H_{e}(z)=\int_{z}^{h_{f}} \rho \varphi(z) d z-\int_{z}^{h_{f}} \alpha \rho \varphi(z)\{1-\varphi(z)\} d z
$$

The last term of Eq. (6) represents the decrease of the head by the movement of gas bubbles.

By the driving force exerted by the head, $H_{e}(z)$, the froth is discharged from the plate in a form of jet. The liquid flow rate per unit weir width, $q$, is given as follows:

$$
q=C \sqrt{2 g} \int_{W}^{h_{f}} \sqrt{\int_{z}^{h_{f}} \varphi(z)[1-\alpha\{1-\varphi(z)\}] d z} d z
$$

where $C$ is a discharge coefficient.

Fig. 7 shows the experimental values of the discharge coefficient $C$. The discharge coefficient has a constant value of 0.2 within the range of experimental conditions, even if the case of outlet weir of $1 \mathrm{~cm}$ height is included.

The values of $C$ may vary with the weir width due to the wall effect. However, as experiments with weirs of different width were not performed in this experiment, the effect of weir width on the value of $C$ was not clarified.

In practical application, Eqs. (5) and (7) are too complicated to be treated conveniently. Fig. 8 shows the computed relation between the froth height and the gas/liquid flow rate by Eqs. (5) and (7). From Fig. $8, \ln \left(h_{f}-W\right)$ is regarded as proportional to $\ln (q)$

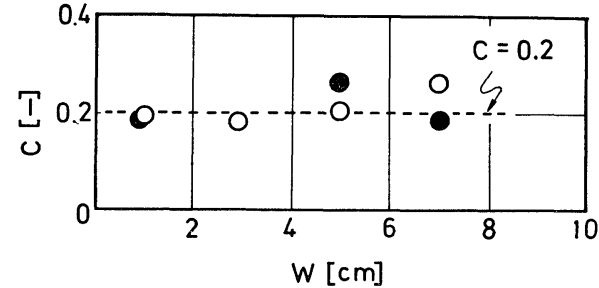

$\bigcirc$ hole diameter $=4 \mathrm{~mm}$, hole diameter $=8 \mathrm{~mm}$

Fig. 7 Discharge coefficient

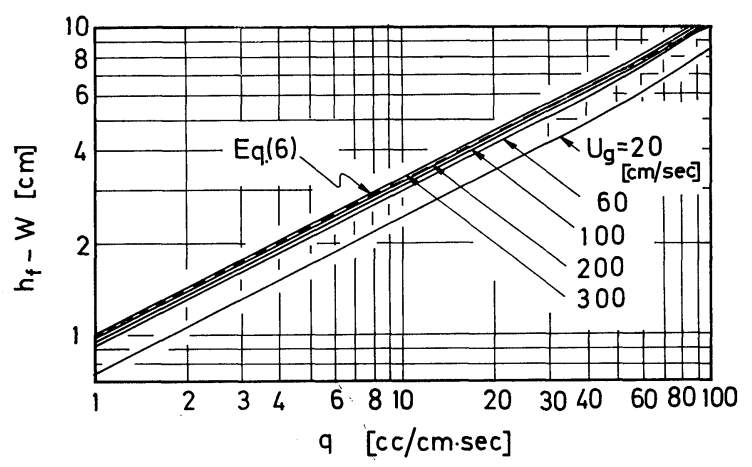

Fig. 8 Relation between froth height and operating variables calculated by Eqs. (5) and (7)

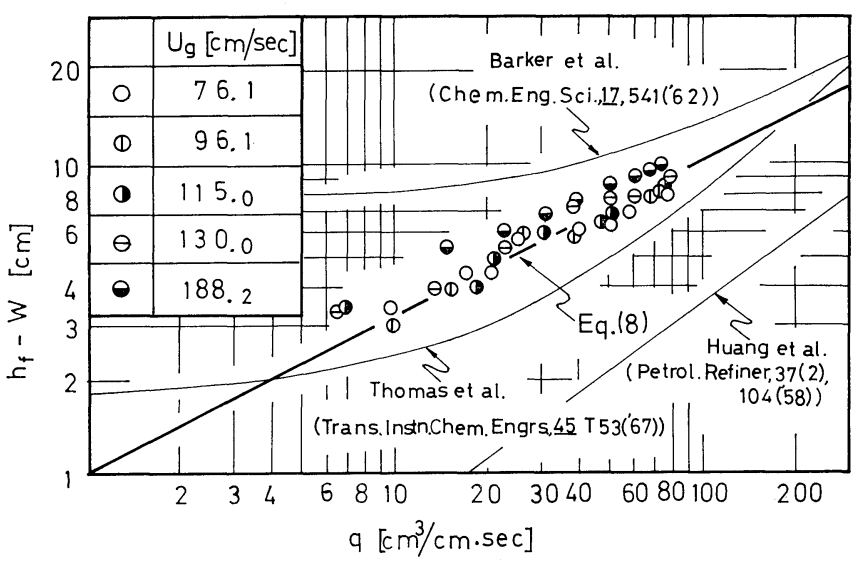

Fig. 9 Experimental confirmation of Eq. (8)

and the proportional constant is approximately $1 / 2$ within the range of experimental conditions.

The relation stated above varies slightly with gas flow rate. However, the difference is slight over the range of gas velocity $U_{g}=100-300 \mathrm{~cm} / \mathrm{sec}$, so the froth height in this range of gas velocity is represented approximately by a function of the liquid velocity only:

$$
h_{f}-W=k \sqrt{q}
$$

where $k$ is a dimensional constant having a value $1.0 \mathrm{sec}^{1 / 2}$. The values of $q, h_{f}$ and $W$ must be measured in the units of $\mathrm{cm}^{3} / \mathrm{sec} / \mathrm{cm}, \mathrm{cm}$ and $\mathrm{cm}$ respectively. Eq. (8) is very simple and convenient for the design of plate towers.

Fig. 9 shows a comparison of the values calculated 
by Eq. (8) with the experimental values. From Fig. 9, it is concluded that Eq. (8) represents the experimental data very well.

To compare the result of this work with previous ones, the calculated froth heights by the correlated equations, which have been obtained under the same conditions as in this experiment, are shown in Fig. 9 by thin solid lines.

Shirotsuka et al. $\left.{ }^{7}\right)$ have reported that the Francis equation, which has been used widely for the design of plate towers, does not hold in the case of large gas velocity. From the results of this work, the result of Shirotsuka et al. is considered to be responsible for the fact that the froth density profiles are regarded as uniform throughout the whole range of the froth layer in the derivation of the Francis equation.

Therefore, it is concluded that the froth height must be related to the operating variables in the consideration of the froth density profiles as shown in this work.

\section{Conclusion}

Local froth density, defined by the volume ratio of liquid to froth at any one point in the froth layer, was measured by a probe method. It was found that the time-averaged froth density is 3-dimensionally distributed, and that the horizontal froth density profiles in the region between the crest of outlet weir and the froth surface are uniform when the height of outlet weir is greater than $3 \mathrm{~cm}$.

The vertical distribution of horizontally uniform froth density is described by a function which is derived on the assumption that the froth density profile is determined under the condition that the total mechanical energy of froth is minimum in the steady state.

By this function, a simple relation between the froth height and the process variables is obtained, by which the experimental data are explained very well.

\section{Nomenclature}

C = discharge coefficient

Fr $\quad=$ Froude number defined as $U_{g}^{2} /\left(g h_{f}^{\prime}\right)$

$g \quad=$ gravity acceleration $\quad\left[\mathrm{cm}^{2} / \mathrm{sec}\right]$

$H_{e}(z) \quad=$ effective head acting on surface $z=z \quad[\mathrm{~cm}]$

$h_{f} \quad=$ froth height $\quad[\mathrm{cm}]$

$h_{f}^{\prime} \quad=$ froth height, $h_{f}-z_{m} \quad$ [cm]

$q \quad=$ liquid flow rate per unit weir width

$U_{g} \quad=$ superficial gas velocity $\quad[\mathrm{cm} / \mathrm{sec}]$

$W \quad=$ height of outlet weir $\quad[\mathrm{cm}]$

$x, y, z=$ co-ordinates from center of a hole $\quad[\mathrm{cm}]$

$z_{m} \quad=$ height from plate surface defined in

$V \quad=$ liquid volume entrained by gas bubbles $\quad\left[\mathrm{cm}^{3}\right]$

$\alpha \quad=$ coefficient defined in Eq. (1)

$\varphi \quad=$ froth density profile $[-]$

$\rho \quad=$ liquid density $\quad\left[\mathrm{g} / \mathrm{cm}^{3}\right]$

\section{Literature Cited}

1) Azbel, D. S.: Intern. Chem. Eng., 3, 319 (1963).

2) Azbel, D. S. and A. N. Zeldin: Theor. Found. Chem. Eng., 5, 785 (1971).

3) Bernard, J. D. T. and R. W. Sargent: Trans. Instn. Chem. Engrs., 44, T314 (1966).

4) Iida, Y., K. Kobayashi and S. Kumagai: Nihon Genshiryoku Gakkaishi, 9, 2 (1967).

5) Kolář, V.: Chem. Eng. Sci., 24, 1285 (1969).

6) Pinczewski, W. V. and C. J. D. Fell: Trans. Instn. Chem. Engrs., 52, 294 (1974).

7) Shirotsuka, T., H. Arakawa and A. Murakami: Preprints for 34th Annual Meeting of The Soc. of Chem. Engrs., Japan, C109, Tokyo (1969).

8) Steiner, L. and V. Kolář: Collection Czechoslov. Chem. Commun., 33, 2207 (1968).

9) Takahashi, T., R. Matsuno and T. Miyahara: J. Chem. Eng. Japan, 6, 39 (1973).

10) Takahashi, T., T. Miyahara and K. Shimizu: ibid., 7, 75 (1974).

11) Tulyaev, Yu. K. and L. S. Akselrod: Theor. Found. Chem. Eng., 6, 134 (1972). 